\title{
Dichrostachys cinerea (L.) Wight et Arn (Mimosaceae) hydro-alcoholic extract action on the contractility of tracheal smooth muscle isolated from guinea-pig
}

\author{
Raissa RR Aworet-Samseny ${ }^{1}$, Alain Souza ${ }^{1}$, Fidele Kpahé ${ }^{2}$, Kiessoun Konaté ${ }^{3}$, Jacques Y Datté ${ }^{*}$
}

\begin{abstract}
Background: Dichrostachys cinerea (L.) Wight et Arn. (Mimosaceae) is largely used in ethno-medically across Africa, and mainly employed for the treatment of asthma in Ivory Coast and Gabon. The paper analyses the relaxation induced by the methanolic extract of D. cinerea (Edici) in the guinea-pig trachea preparations (GPTPS). Purpose: This study aimed to bring out the scientific basis to the use of this plant leading to the validation of this phytomedicine.

Method: The aorta obtained from guinea-pigs was immediately placed in a Mac Ewen solution. Experiments were performed in preparations suspended between two L-shaped stainless steel hooks in a $10 \mathrm{ml}$ organ bath containing Mac Ewen solution. The isometric contractile force of the aorta strips of guinea-pig were recorded by using a strain gauge. The different drugs were directly administered into the organ bath and the magnitude of GPTPs was evaluated.

Results: Phytochemical analysis of the methanolic extract of Dichrostachys cinerea (Edici) using chemical methods revealed the presence of flavenoids, tannins, sterols, triterpenes and polyphenols. Pharmacological studies performed in GPTPs show that of Dichrostachys cinerea $(0.1 \mathrm{mg} / \mathrm{ml}-2 \mathrm{mg} / \mathrm{ml})$ evoked a broncho-constriction in GPTPs. Whereas, at concentration up to $2 \mathrm{mg} / \mathrm{ml}$, Edici induced a significant dose-dependent relaxation in the GPTPs. KCl-, ACh- or histamine-evoked contractions of isolated trachea was significantly inhibited by increasing concentrations of Edici (3.5-10 mg/ml). Edici $(10 \mathrm{mg} / \mathrm{ml})$ as well as promethazine $(0.25 \mathrm{mg} / \mathrm{ml})$ significantly inhibited contractions induced by increasing concentrations of histamine $\left(1 \times 10^{-7}-1 \times 10^{-4} \mathrm{mg} / \mathrm{ml}\right)$. In the presence of atropine at a concentration of $10^{-}$ ${ }^{6} \mathrm{mg} / \mathrm{ml}$, contractile response curve (CRC) evoked by ACh $\left(1 \times 10^{-5}-1 \times 10^{-2} \mathrm{mg} / \mathrm{ml}\right)$ was significantly abolished in concentration-dependent manner. Edici did not significantly reduced ACh evoked contraction $\left(10^{-5}-10^{-2} \mathrm{mg} / \mathrm{ml}\right)$.

Conclusion: These observations suggest that Edici could act through two mechanisms: firstly by activation of $\beta$-adrenergic or histaminergic receptors; and secondly muscarinic receptors may not be greatly involved, that justifying the use of the extract in traditional Medicine in Africa.
\end{abstract}

\section{Background}

Asthma is a chronic inflammatory disorder of the airways characterized by airways obstruction, airways hyper-responsiveness, excessive mucous secretion and cough [1]. Nowadays, asthma represents a public health problem in African countries with a prevalence ranging from 1 to $12 \%$ according to WHO estimation.

\footnotetext{
* Correspondence: dattejy@gmx.net

${ }^{2}$ Laboratoire de Nutrition et de Pharmacologie, UFR BioSciences, Université de Cocody, Abidjan 22 BP: 582 Abidjan -Côte d'lvoire

Full list of author information is available at the end of the article
}

Although asthma cannot be totally cured, appropriate management can control the disease and enable people to enjoy a good quality of life. Short-term medications are used to relieve symptoms. People with persistent symptoms have to take long-term medication daily to control the underlying inflammation and to prevent symptoms and exacerbations.

Folk medicine provides many phytomedicines which represent a significant alternative for the management of this affection in several communities around the world. In India, Solanum xanthocarpum is used for the management

\section{Biomed Central}


of bronchial asthma [2]; in Europe Inula helenium, has been used since the middle ages for its expectorant properties, it is known as a stimulant to the respiratory system and has long been used to treat asthma and chronic bronchitis [3]. In Ivory Coast traditional medicine, air-dried powdered stem bark of Dichrostachys cinerea is used by inhalation for the treatment of this airways affection $[4,5]$.

Dichrostachys cinerea which belongs to the family of mimosaceae is also used for the treatment of wounds, rheumatism and renal troubles [6]. Pharmacological report on D. cinerea has shown antibacterial effect $[7,8]$ and antiviral. Several authors have shown that the species inhibit protein farnesyl-transferase activity $[9,10]$. Moreover, chemical studies revealed the presence of a new isomer of mesquitol (a main active principle), which shown free-radical scavenging property and $\alpha$-glucosidase inhibitory activities [11].

Phytochimical studies performed on D. cinerea extracts have revealed the presence of tannins, sterols and triterpenes, of reductionist compounds, polyphenols, flavenoids as well as of cardiotonic heterosides [12].

Based on the fact that guinea-pig airways display many anatomical, physiological and pharmacological attributes of human airways [13] and that the smooth muscle of trachea represent an ideal model for the study of the airway regulation [14], the hydro-alcoholic extract of $D$. cinerea was performed on the isolated trachea rings of the guinea-pig in order to evaluate its therapeutic potential for the management of asthma. Our work aims to bring out scientific support to the use of Dichrostachys cinerea as antiasthmatic remedy in folk medicine. Since tracheal muscle cells of guinea-pig have similar physiological properties than human ones [15,16], the present investigation is a comparative study of Dichrostachys cinerea methanolic extract to histamine in isolated guinea-pig's tracheal smooth muscle.

\section{Methods}

\section{Plant material}

Dichrostachys cinerea (L.) Wight et Arn. (Mimosaceae) is a shrub up to eight feet high, with branches ending in thorns. The leaves are bipinnate, each pinna bearing a gland. The pendant flowers $2.5 \mathrm{~cm}$ long are composed of an upper and a yellow hermaphrodite bottom sterile from purple to pink. The fruit pods are twisted, indehiscent, a decorative effect original. It also comes growing on heavy soils are locally abundant and characteristic of savannas. This species occurs in Central, Southern and tropical Africa.

Fresh roots barks of Dichrostachys cinerea were collected at Essassa (December 2009, rain season) in the province of Estuaire (Gabon). The plants were authenticated by Mr Raoul Niangadouma a botanist of Gabon National Herbarium (IPHAMETRA/CENAREST). A voucher specimen (H.P Bouroubou 387, M.S.M Sosef $n^{\circ}: 894$, M.SM 1097) were deposed in this department.

\section{Preparation of the plant extract}

The sun-dried roots barks of Dichrostachys cinerea were cut into small pieces, using a micro-crusher (Retsch SK 100 Confort Geissen Germany). The fine powder obtained was firstly macerated (100 g) for 24 hours in petrol ether $(500 \mathrm{ml})$ using magnetic stirrer to remove oils, chlorophylls. Solvent was removed and the solid remainder was collected and dried at room temperature. It was macerated again in methanol $(500 \mathrm{ml})$ for 24 hours. The supernatant was filtered with Wattman paper and it was evaporated using Rotavapor (Laborota 4002-Control Heidolph, Germany). The methanolic extract of the plant (1.53 g) was obtained and stored at $4^{\circ} \mathrm{C}$ until experiments.

\section{Phytochemical screening}

Phytochemical study of the methanolic extract was performed using described classical procedures $[17,18]$. Chemical groups characterized were alkaloids, tannins, flavonoids, polyphenols, saponins, sterols and triterpenes, glycosides, sugars.

\section{Animals}

Guinea-pigs (Cavia porcellus) weighing 300-500 g, were used for pharmacological studies. Animals were raised at room temperature $\left(27 \pm 2^{\circ} \mathrm{C}\right)$ with a natural lightdark cycles with food and water ad-libitum. Animals were cared for and treated according to the principles for the care and use of laboratory animals for biomedical research approved by the ethical committee of Cocody University, Abidjan.

\section{Preparation of isolated tracheal strips}

The methods were previously described $[19,20]$. The animals were sacrificed by a blow on the head and were ex-sanguinated. Trachea was quickly dissected and cleaned of connective tissues. The isolated trachea was cut transversally into small rings which were transferred in a Petri dish containing a Mac Ewen solution (mM) with following composition: $\mathrm{NaCl}, 130 ; \mathrm{KCl}, 5.6 ; \mathrm{CaCl}_{2}$, 2.6; $\mathrm{NaH}_{2} \mathrm{PO}_{4}, 0.91 ; \mathrm{NaCO}_{3} \mathrm{H}, 11.9 ; \mathrm{MgCl}_{2}, 0.24$; glucose, 11 . The preparations were transferred in normal Mac Ewen solution.

\section{Measurement of isometric tension}

Tracheal isolated preparations were mounted in $10 \mathrm{ml}$ jacketed tissue baths by suspending them between two L-shaped stainless steel hooks. The lower hooks were attached to stationary support such that they could be positioned at the bottom of the bath chambers. The upper hooks were attached to force-displacement transducers (F30, type 372). The bath chamber contained the 
appropriate Mac Ewen solution $\left(37 \pm 0.5^{\circ} \mathrm{C}\right)$ constantly bubbled with $95 \% \mathrm{O}_{2}-5 \% \mathrm{CO}_{2}$, giving a $\mathrm{pH}$ of 7.4. Isometric force was measured and recorded using a Multipen Recorder Rikadenki polygraph (Hugo Sachs Instruments, Freiburg, Germany). A pre-load of $1 \mathrm{~g}$ was applied. After mounting, strips were equilibrated for 30 min. Changes in isometric force were measured and recorded by means of a force transducer.

\section{Experimental Protocol}

The effects of Edici were evaluated on contractile activity of isolated tracheal strips. The same protocol was used [21]. The rings were mounted as already described [22]. After the $30 \mathrm{~min}$ period of equilibration, the contractile response to depolarizing potassium solution was assessed as a test for viability. The depolarizing $\mathrm{KCl}$ solution $(80 \mathrm{mM})$ had the same composition as the Mac Ewen solution used, except for the $\mathrm{NaCl}$ that had been completely replaced by an equimolar amount of $\mathrm{KCl}$. The GPTPs were washed with Mac Ewen solution four times and re-equilibrated for another $30 \mathrm{~min}$. Edici was directly administered for $4 \mathrm{~min}$ in the organ bath and the magnitude of the contractile activity of the GPTPs was evaluated. After equilibration for $30 \mathrm{~min}$, cconcentration-response curve (CRC) for plant extract, histamine or ACh were obtained by cumulatively added increasing concentrations.

Edici was directly administrated into the organ bath and the contractile force was evaluated. In our experiments, the cumulative CRC for either Edici or salbutamol was recorded. In a second step, CRCs for Edici was obtained in GPTPs pre-contracted either with $\mathrm{KCl}$, histamine or Acetylcholine (ACh). To know if Edici acts via histaminergic receptors stimulation, CRC for histamine was realized in GPTPs pre-treated for $15 \mathrm{~min}$ with either Edici employed at a unique concentration of 10 $\mathrm{mg} / \mathrm{ml}$ or promethazine $(0.25 \mathrm{mg} / \mathrm{ml})$. In order to study the involvement of cholinergic receptors in the plant extract-induced the trachea relaxation, CRC acetylcholine was realized cumulatively in GPTPs rings pre-incubated with either Edici or atropine $\left(1 \times 10^{-5} \mathrm{mg} / \mathrm{ml}\right)$, cholinoceptors antagonist.

Cumulative CRC were analysed using GraphPad software (GrapPad Software Inc., San Diego, CA, USA) to determine $\mathrm{pEC}_{50}$ values [negative logarithm of the concentration eliciting $50 \%$ of the maximal contractile response (E-max)]. When a plateau in the concentration response curve was not reached, the response observed with the highest concentration of Edici used $(10 \mathrm{mg} / \mathrm{ml})$ was considered as E-max.

\section{Drugs}

Acetylcholine, histamine and atropine were purchased from Sigma chemical (St. Louis Mo). Promethazine were obtained from Prolabo (France). Salbutamol [23] was purchased from GlaxoSmithKline (Parma, Italy). All drugs were dissolved in distilled water for the preparation of stock solution.

\section{Statistical analysis}

All values in the text and illustrations are presented as mean \pm SEM, with $n$ representing the number of different preparations. Differences between $\mathrm{pEC}_{50}$ and E-max values of the compounds were evaluated with Dunnett's $t$-test, once an analysis of variance (ANOVA) for data had revealed that the samples represented different populations. Values of $p<0.05$ were considered to indicate significant differences.

\section{Results}

\section{Phytochemical screening}

Phytochemical study of Dichrostachys cinerea shows that the methanolic extract is rich in phenol compounds (phenols compounds and flavenoids). Tannins, sterols and triterpenes were also found in this extract.

\section{Effect of extract of Dichrostachys cinerea on isolated guinea pig tracheal preparations}

As shown in table 1, the hydro-alcoholic extract of Dichrostachys cinerea (Edici) exerted a biphasic action on a tracheal smooth muscle isolated from the guineapig. Edici at concentrations ranging from $0.1 \mathrm{mg} / \mathrm{ml}$ to $2 \mathrm{mg} / \mathrm{ml}$ induced the GPTPs contractions from $134 \pm$ $32 \mathrm{mg}$ (control value) to $353 \pm 49 \mathrm{mg}(\mathrm{p}<0.05)$. However, at concentrations up to $2 \mathrm{mg} / \mathrm{ml}$, Edici evoked significantly a dose-dependent vasorelaxation of the GPTPs smooth muscle from $-134 \pm 49 \mathrm{mg}$ to $-276 \pm 51 \mathrm{mg}$ $(\mathrm{p}<0.05)$ at concentrations of $3.5 \mathrm{mg} / \mathrm{ml}$ and $10 \mathrm{mg} /$ $\mathrm{ml}$, respectively (Table 1 ).

Similar results were obtained with the pharmacological reference drug, salbutamol, a short-acting $\beta_{2}$-adrenergic receptor agonist used for the relief of bronchospasm in conditions such as asthma and chronic obstructive pulmonary [30]. The table 2 shows the effect of cumulative doses of salbutamol on the GPTPs. Salbutamol at concentrations of $2.3 \times 10^{-6} \mathrm{mg} / \mathrm{ml}$ to $2.3 \times 10^{-5} \mathrm{mg} / \mathrm{ml}$ induced a contraction of the GPTPs from $109 \pm 15$ to $183 \pm 9.9$ $\mathrm{mg}(\mathrm{p}<0.01)$. At a concentration up to $2.3 \times 10^{-5} \mathrm{mg} / \mathrm{ml}$, salbutamol caused relaxation of the GPTPs. The both concentrations of salbutamol $\left(2.3 \times 10^{-4} \mathrm{mg} / \mathrm{ml}\right.$ and $2.3 \times 10^{-3} \mathrm{mg} / \mathrm{ml}$ ) caused a significant relaxation of the GPTPs smooth muscle of $-85 \pm 7.3 \mathrm{mg}$ and $-670 \pm 20 \mathrm{mg}$ $(\mathrm{p}<0.01)$, respectively (Table 2 ).

Original tracings of the guinea pig tracheal activity in the presence of Edici on histamine $(\mathrm{H}), \mathrm{KCl}$ - or $\mathrm{ACh}$-induced contractions were recorded as shown on Figures 1A, B and $1 \mathrm{C}$, respectively. These effects were graphical represented in figure 1D. The maximum responses to $\mathrm{KCl}$ 
Table 1 Concentrations of Dichrostachys cinerea (Edici) ranging from $0.1 \mathrm{mg} / \mathrm{ml}$ to $10 \mathrm{mg} / \mathrm{ml}$ on contractile force of strips isolated from guinea-pigs tracheal smooth muscle

\begin{tabular}{llllll}
\hline $\mathrm{C}[\mathrm{mg} / \mathrm{ml}]$ & $\mathbf{0 . 1}$ & $\mathbf{1}$ & $\mathbf{2}$ & $\mathbf{3 . 5}$ & $\mathbf{1 0}$ \\
\hline $\mathrm{CF}[\mathrm{mg}]$ & $+134 \pm 32$ & $+215 \pm 61$ & $+353 \pm 49$ & $-134 \pm 49$ & $-276,33 \pm 51$ \\
\hline
\end{tabular}

$\mathrm{C}=$ concentration; $\mathrm{CF}=$ Contractile force,

Values are mean \pm SEM, $n=4$.

(80 mM), histamine $\left(5 \times 10^{-4} \mathrm{mg} / \mathrm{ml}\right)$ or to ACh $\left(1 \times 10^{-1}\right.$ $\mathrm{mg} / \mathrm{ml})$ were significantly reduced by Edici $\left(1 \times 10^{-6} \mathrm{mg} /\right.$ $\mathrm{ml}$ ). Indeed, respective E-maximums responses induced by $\mathrm{KCl}$, histamine or by $\mathrm{ACh}$ were significantly blocked from $256 \pm 16 \mathrm{mg}$ (control value) to $-110 \pm 7.7 \mathrm{mg}$ for $\mathrm{KCl}$ (p < $0.01 ; \mathrm{EC}_{50}$-value $\left.=0.54 \times 10^{-4} \mathrm{mg} / \mathrm{ml}\right)$, from $231 \pm 14 \mathrm{mg} /$ $\mathrm{ml}$ to $-183 \pm 11.1 \mathrm{mg} / \mathrm{ml}$ for 5 -HT $\left(\mathrm{P}<0.01 ; \mathrm{EC}_{50}\right.$-value $=$ $\left.0.28 \times 10^{-4} \mathrm{mg} / \mathrm{ml}\right)$, induced contracts and from $1268 \pm 30$ $\mathrm{mg} / \mathrm{ml}$ to $48 \pm 9.1 \mathrm{mg}$ for $\mathrm{ACh}\left(\mathrm{p}<0.01 ; \mathrm{EC}_{50}\right.$-value $=$ $\left.0.50 \times 10^{-4} \mathrm{mg} / \mathrm{ml}\right)$.

Comparative study of extract of Dichrostachys cinerea and promethazine on histamine-induced contractions on isolated guinea pig trachea strips

Histamine $\left(1 \times 10^{-7}-1 \times 10^{-4} \mathrm{mg} / \mathrm{ml}\right)$ induced a concentration-dependent increase of the GPTPs. The maximum value (E-max) recorded was $420 \pm 60 \mathrm{mg}\left(\mathrm{EC}_{50}: 9.8 \times 10^{-}\right.$ ${ }^{7} \mathrm{~m} / \mathrm{ml}$ ). As shown in figure $2 \mathrm{~A}$, in the presence of Edici $(10 \mathrm{mg} / \mathrm{ml})$, the contractions of the GPTPs induced by histamine were significantly reduced in a concentrationdependent fashion $(\mathrm{p}<0.05)$ compared to maximum response of control group. The E-max in these conditions was $162 \pm 16.33 \mathrm{mg}$ with an $\mathrm{EC}_{50}$-value of $2.1 \times$ $10^{-7} \mathrm{mg} / \mathrm{ml}$. Similarly, results were obtained with promethazine at a single concentration of $0.25 \mathrm{mg} / \mathrm{ml}$. Contractions elicited by histamine was significantly blocked in the presence of promethazine, a $\mathrm{H}_{1}$-histaminergic receptor antagonist $(\mathrm{p}<0.05)$ (Figure $2 \mathrm{~B})$. The E-max of the GPTPs tension of histamine was drastically reduced to $183 \pm 9.9 \mathrm{mg}\left(\mathrm{EC}_{50}: 1.9 \times 10^{-6} \mathrm{mg} / \mathrm{ml}\right)$.

\section{Comparative effects of extract of Dichrostachys cinerea} and atropine in ACh-induced contractions of the guinea pig trachea preparations

Acetylcholine $(\mathrm{ACh})$ in concentration ranging from $1 \times 10^{-5} \mathrm{mg} / \mathrm{ml}$ to $1 \times 10^{-2} \mathrm{mg} / \mathrm{ml}$, added cumulatively on the organ bath, induced a significant increase of

Table 2 Concentrations of salbutamol ranging from $2.3 \times 10^{-6} \mathrm{mg} / \mathrm{ml}$ to $2.3 \times 10^{-3} \mathrm{mg} / \mathrm{ml}$ on contractile force of strips isolated from guinea-pigs tracheal smooth muscle

\begin{tabular}{lllll}
\hline $\mathrm{C}[\mathrm{mg} / \mathrm{ml}]$ & $2.3 \times 10^{-6}$ & $2.3 \times 10^{-5}$ & $\mathbf{2 . 3 \times 1 0 ^ { - 4 }}$ & $\mathbf{2 . 3 \times 1 0 ^ { - 3 }}$ \\
\hline $\mathrm{CF}[\mathrm{mg}]$ & $+109 \pm 15$ & $+183 \pm 9.9$ & $-85 \pm 7.3$ & $-670 \pm 20$
\end{tabular}

$\mathrm{C}=$ concentration; $\mathrm{CF}=$ Contractile force,

Values are mean \pm SEM, $\mathrm{n}=4$ contractions of the GPTPs in a concentration-dependent manner. The $\mathrm{EC}_{50}$-value was $6.62 \times 10^{-4} \mathrm{mg} / \mathrm{ml}$. The Maximal value of contraction (E-max) of the concentrationresponse curve for $\mathrm{ACh}$ in of the GPTPs in the presence of atropine $\left(1 \times 10^{-5} \mathrm{mg} / \mathrm{ml}\right)$ was reduced to $51.14 \%$. AChinduced contractions were significantly inhibited. The $\mathrm{EC}_{50^{-}}$-value was $6.62 \times 10^{-4} \mathrm{mg} / \mathrm{ml}$ (Figure 3A). Similar results were obtained in the pre-treatment of the GPTPs with $\mathrm{EdiCi}$ at a unique concentration of $10 \mathrm{mg} / \mathrm{ml}$. The E-max of the concentration-response curve for $\mathrm{ACh}$ shifted rightwards significantly. A reduction of E-maxvalue was $25.57 \%$ compared to control value. Moreover, the $\mathrm{EC}_{50}$-value was $3.2 \times 10^{-4} \mathrm{mg} / \mathrm{ml}$ in the absence of Edici, and $8.3 \times 10^{-5} \mathrm{mg} / \mathrm{ml}$ in the presence of EdiCi (Figure 3B).

\section{Discussion}

The powder of sun-dried root barks of Dichrostachys cinerea is usually used in folk medicine for the treatment of asthma. The bark powder of Dichrostachys cinerea's root is used in nasal instillation.

In the present work, phytochemical investigation performed on the plant species collected in Libreville (Gabon) forest revealed the presence of bioactive compounds such as alkaloids, flavenoids, tannins, sterols and triterpenes, phenolic compounds. These results are in accordance with those showing the presence of terpenoids, sterols and tannins in the leaves and fruits. Pharmacological study showed a transient bronchoconstriction followed by a sustained bronchodilation in the airway smooth muscle. Similar results were demonstrated with Parquetina nigrescens (Periplocaceae) on smooth muscle preparations [24]. These results suggest that constituents in the extract of $D$. cinerea may exert airways regulation.

It is well established that the salbutamol ( $\beta 2$-adrenergic receptor agonist) activity is due to the stimulation $\beta$-adrenergic receptors [25]. The fact that $D$. cinereaevoked biphasic action and mainly bronchodilatory effect was similar to that induced by salbutamol, allowed us to suggest that $D$. cinerea's active principles may act via $\beta$-adrenergic receptors to elicit the relaxation of the trachea smooth muscle. In the GPTPs, salbutamol produces more relaxant effect than salmeterol, suggesting that salmeterol is a partial beta-2 agonist. Very high concentrations of salmeterol as well of salbutamol may induce non-beta adrenoceptor mediated relaxation. 


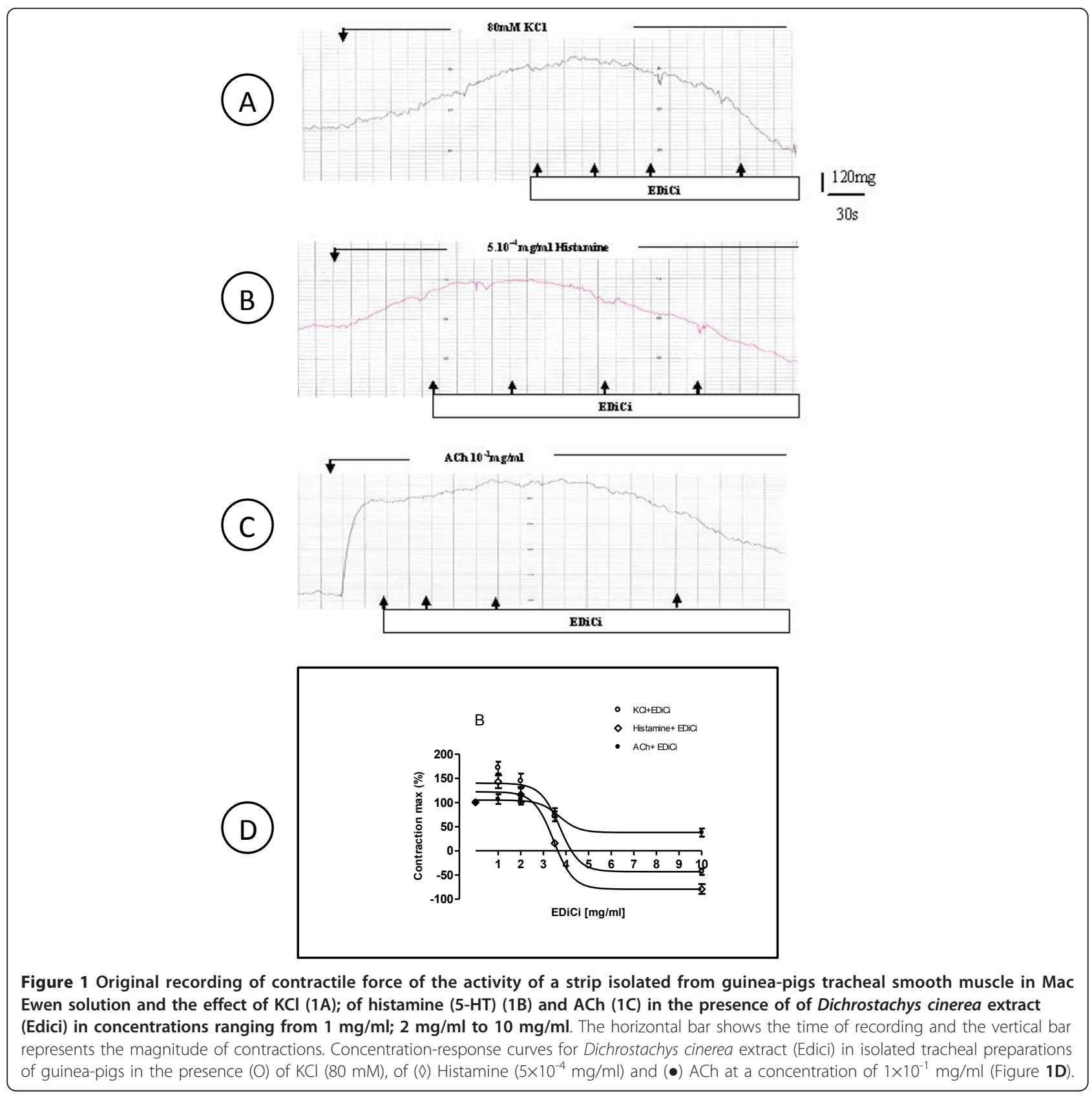

There is no pronounced difference in the magnitude of antagonism against carbachol induced contractions between salmeterol and salbutamol [26]. Since, the plant extract exhibited a direct relaxation of normal smooth muscles of the trachea [27] and in addition, it induced a concentration-dependent relaxation of the GPTPs precontracted with $\mathrm{KCl}$ or with histamine. However, $D$. cinerea hydro-alcoholic extract moderately reduced the bronchoconstriction evoked by acetylcholine. This result did not suggest a high inhibitory effect the plant extract actives principles on the cholinergic receptors. Since, ACh still induced a significant bronchoconstriction on the isolated trachea pre-treated with the plant extract; while atropine, an antagonist of cholinergic muscarinic receptors totally abolished the ACh-evoked at the same conditions. Indeed, the agonist of cholinergic receptors such as ACh evoked bronchospasm which is inhibited by anticholinergic drugs such as atropine [28]. Anti-cholinergic drugs block muscarinic effect of ACh on the receptors of postjunctional membranes and so inhibit the answer of the post ganglionic parasympathetic nerve. The loss of $\mathrm{M}_{2}$ muscarinic receptor function occurs in asthmatics and it contributes to bronchial hyper -responsiveness and it is not a chronic feature of asthma, and instead 


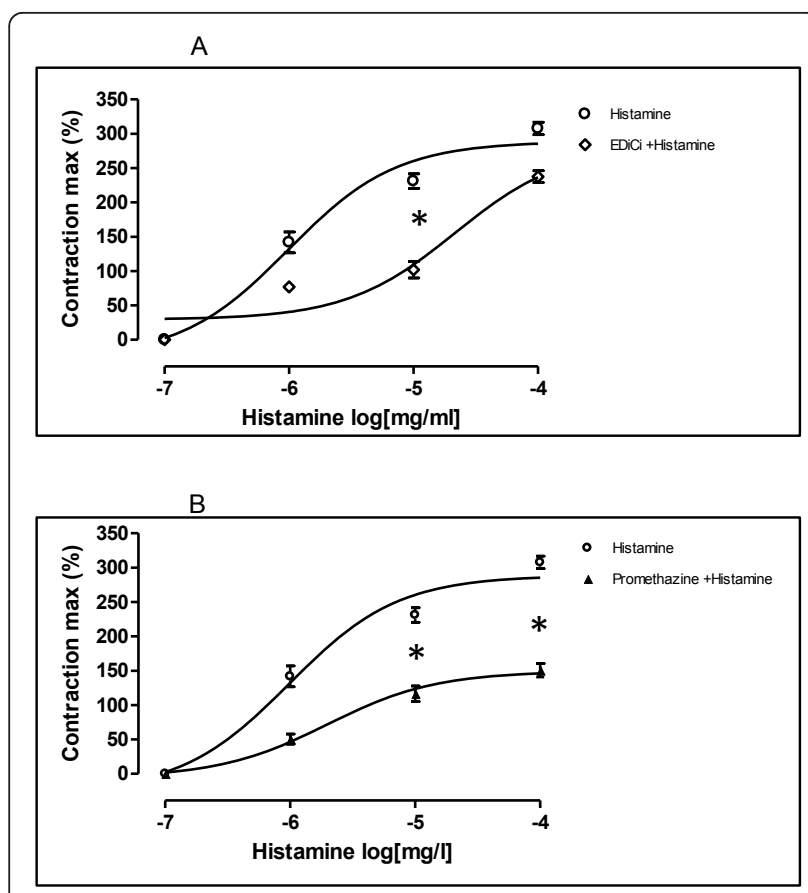

Figure 2 Concentration-response curves for histamine in isolated tracheal preparations of guinea-pigs in the absence $(0)$ and presence $(0)$ of Edici $(10 \mathrm{mg} / \mathrm{ml})(2 \mathrm{~A})$, and in the presence $(\Delta)$ of promethazine at a concentration of $0.25 \mathrm{mg} / \mathrm{ml}$ (2B). Concentration of histamine are expressed as the $\log 10$ of the molar concentration. Each Point represents the mean values obtained using 6 rings. Each obtained from different animal. Brackets indicate SEM $(n=4-6)$.

it characterizes asthma exacerbation. The loss of $\mathrm{M}_{2}$ muscarinic receptor function in children and adults happens during antigen bronchoprovocation or during exposition of asthmatics to ozone. The research findings support the hypothesis that beta2-adrenoceptor agonist drugs, administered over time in vivo or in vitro, induce a transient hyperresponsiveness of airway smooth muscle to cholinergic bronchoconstrictor stimuli $[29,30]$. Histamine-evoked broncho-constriction is due to the activation of $\mathrm{H}_{1}$-histaminergic receptors and is blocked by antihistaminergic drugs such as promethazine [31,32]. Whereas, $\mathrm{KCl}-$ induced broncho-constriction results from the depolarization of cell membrane which causes the augmentation of calcium influx through voltage operated calcium channels leading to the rise of intracellular calcium level [33]. Moreover, the acute and relatively refractory hyperkalemia can develop. In such situations, incorporating salbutamol with a conventional anti-hyperkalemia strategy can provide an effective therapeutic option to treat hyperkalemia, even during the anhepatic stage $[34,35]$. Our study showed that, the plant extract, totally inhibited the $\mathrm{KCl}$-evoked contractions and similarly to promethazine, it abolished histamine-evoked contractions suggesting the involvement of different possible mechanisms: a potassium channels
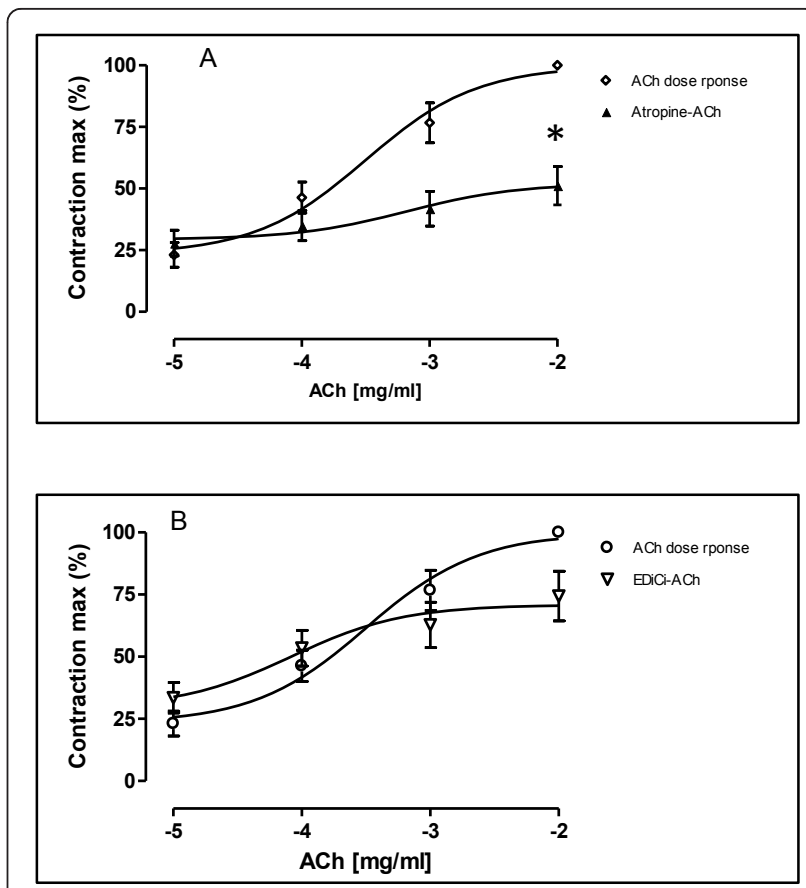

Figure 3 Concentration-response curves for ACh in isolated tracheal preparations of guinea-pigs in the absence $(\Delta)$ and in the presence $(\Lambda)$ of atropine $(0.25 \mathrm{mg} / \mathrm{ml} ; 3 \mathrm{~A})$, and pretreatment $(\Delta)$ with Edici at a single concentration of $10 \mathrm{mg} / \mathrm{ml}$ (3A). Concentration of ACh are expressed as the $\log 10$ of the molar concentration. Each Point represents the mean values obtained using 6 rings. Each obtained from different animal. Brackets indicate SEM $(n=4-6)$.

opening effect, an inhibitory effect on calcium channels and/or an antagonistic effect on histaminergic receptors. Further studies are required to clarify the contribution of these mechanisms of action.

Pathophysiology of asthma is characterized by two phases, namely a bronchoconstriction followed by a special type inflammation [36]; the bronchoconstriction being the main component of the immediate phase of asthmatic response on multiple stimuli [37]. Overall, the plant extract's actives principles-evoked relaxation on pre-contracted tracheal chains (pathological tissues) highlighted a bronchospasmolytic action that may support its potential usefulness in the treatment of bronchoconstrictive diseases. Regarding the phytochemical composition of the plant extract, active constituents in the plant extract such as terpenoids may be responsible for the bronchodilator action [38]. In addition, flavonoids and polyphenols contents in plant extract may contribute for the biological activities of the extract and thus the therapeutic potential of $D$. cinerea for the management of asthma. Since, these phytoconstituents have spasmolytic action on smooth muscle [39,40], antioxidant and anti-inflammatory activities $[41,42]$. 
Promethazine or Edici associated to histamine induced a relaxation of the GPTPs smooth muscle. The Emax values were at half decrease. It is well known that promethazine is a phenothiazine used as an anti-histamine. Antihistamines such as promethazine compete with histamine for one of the receptors for histamine (the $\mathrm{H}_{1}$ receptor) on cells. Promethazine also blocks the action of acetylcholine (anticholinergic effect). The same observation was done with the interaction ACh-Atropine or ACh-Edici. The values of $\mathrm{EC}_{5}$ and $\mathrm{EC}_{50}$ were very influenced in the presence of our extract. Similar results were obtained with seeds aqueous extract from Acacia nilotica [43]. Moreover, experiments with the stem bark of Mangifera indica Linn. showed similar results [44]. Our experiments suggest that the aqueous extract of $D$. cinerea could block both the histaminic and muscarinic receptors on guinea-pig trachea.

\section{Conclusion}

From the present study, it could be concluded that Dichrostachys cinerea possesses marked bronchorelaxation property complying many facets such as acting via adrenergic receptors activation, potassium channels opening effect, calcium channels blocking and/or by antagonistic action on $\mathrm{H}_{1}$-histaminergic receptors justifying its use for the management of asthma in folk medicine. This fact is reinforced by well documented antioxidant and anti-inflammatory properties of its active ingredients. The results corroborate with the traditional use of $D$. cinerea in the treatment of asthma.

\section{Acknowledgements}

The authors thank Miss Akalé Joachime for her help in assistance during the lab works. We are grateful to the Agence Universitaire Francophone (AUF) in Abidjan for the financial support

\section{Author details}

${ }^{1}$ Institut de Pharmacopée et de Médecine Traditionnelle, Centre National de la Recherche Scientifique et Technologique (Cenarest) BP: 1156 Route de Sibang 3 Libreville Gabon. ${ }^{2}$ Laboratoire de Nutrition et de Pharmacologie, UFR BioSciences, Université de Cocody, Abidjan 22 BP: 582 Abidjan -Côte d'Ivoire. ${ }^{3}$ Laboratoire de Biochimie et de chimie Appliquées, UFR Science de la Vie et de la Terre, Université de Ouagadougou, 09 BP 848 Ouagadougou 09 Burkina Faso.

\section{Authors' contributions}

RRRAS, FK and KK carried out the experimental studies and drafted the manuscript. AS and JYD played a role in the writing and editing of the manuscript. AS involved in coordination of study done in Gabon. JYD conceived of the study, participated in the design and coordination of the study, supervised the study and revised the manuscript. All authors read and approved the final manuscript.

\section{Competing interests}

The authors declare that they have no competing interests.

Received: 21 September 2010 Accepted: 17 March 2011 Published: 17 March 2011
References

1. WHO: Fact Sheet $n^{\circ}$ 307. 2008

2. Vadnere GP, Gaud RS, Singhai AK: Evaluation of anti-asthmatic property of Solanum xanthocarpum flower extracts. Pharmacologyonline 2008, 1:513-522

3. Okuda T: "Encyclopedia of Natural Medicine". Hirokawa, Tokyo, Japan; 1986, 64.

4. Adjanohoun EJ, Aké-Assi L: Contribution au recensement des plantes médicinales de Côte d'Ivoire. Collection médecine traditionnelle et pharmacopée. Centre Nat Florist Univ Abidjan 1979, 358.

5. Ouattara $D$ : Recensement d'espèces végétales employées dans le traitement de I'Asthme bronchique: cas du District d'Abidjan (Côte d'Ivoire). Mémoire de maîtrise de botanique et de phytothérapie Université d'Abobo-Adjamé; 2007, 34

6. Eisa MM, Almagboul AZ, Omer MEA, Elegami AA: Antibacterial activity of Dichrostachys cinera. Fitoterapia 2000, 71:324-327.

7. Kambizi L, Afolayan AJ: An ethnobotanical study of plants used for the treatment of sexually transmitted diseases (njovhera) in Guruve District. J Ethnopharmacol 2001, 77:5-9.

8. Kudi AC: Antiviral activity of some Nigerian medicinal plant extracts. Ethnopharmacol 1999, 68:298-294

9. Jagadeeshwar RR, Ashok K, Tiwari, Sampath U, Kumar KU, Reddy SV, Amtul ZA, Madhusudana RJ: Novel 3-0-Acyl Mesquitol Analogues as FreeRadical Scvengers and Enzyme Inhibitors: Synthesis, Biological Evaluation and Structure-Activity Relationship. Bioorganic and Medicinal Chemistry letters 2003, 13:2777-2780

10. Achidi AV, Kinnoudo C: Antiviral properties of extracts of Dichrostachys glomerata. Fascicule de brevet européen, Bulletin 2008, 2008-07.

11. Long C, Marcourt L, Raux R, David B, Gau C, Menendez C, Gao M, Laroche MF, Schambel P, Delaude C, Ausseil F, Lavaud C, Massiot G: Meroterpenes from Dichrostachys cinerea inhibit protein farnesyl transferase activity. J Nat Prod 2010, 72(10):1804-15, Erratum in: J Nat Prod. 2010 25;73 (6):1192.

12. Tillement JP, Albengres E: Pharmacological approach to the rational use of cardiotonic heterosides. Coeur Med Interne 1977, 16:239-48.

13. Mazzone SB, Canning BJ: Guinea pig model of asthma. Current Protocols in Pharmacology 2002, 5(26):1-5

14. Canning BJ, Undem BJ: Evidence that distinct neural pathways mediate parasympathetic contractions and relaxations of guinea-pig trachealis. $J$ Physiol 1993, 471:25-40.

15. Honda K, Tomita T: Electrical activity in isolated human tracheal muscle. Jpn J Physiol 1987, 37:333-6.

16. Ressmeyer AR, Larsson AK, Vollmer E, Dahle'n SE, Uhlig S, Martin C: Characterisation of guinea pig precision-cut lung slices: comparison with human tissues. Eur Respir J 2006, 28:603-611.

17. Harborne JB: Phytochemical Methods: A guid to Modern Techniques of Plant Analysis. Chapman and Hall, Londres; 1973, 279.

18. Konan AB, Datté JY, Yapo PA: Nitric oxide pathway-mediated relaxant effect of aqueous sesame leaves extract (Sesamum radiatum Schum. \& Thonn.) in the guinea-pig isolated aorta smooth muscle. BMC Complement Altern Med 2008, 27(8):23.

19. Datté JY, Gohlke P, Pees C, Ziegler A: Short treatments of normotensive and hypertensive rats by angiotensin II and nitric oxide inhibitor induce an increase of nor-adrenaline sensitivity in isolated vena portae preparations. Pharmacol Res 2000, 41:641-8.

20. Datté JY, Gohlke P, Pees C, Ziegler A: AT receptor inhibition affects the noradrenaline sensitivity in isolated portal vein of normotensive rat. Clin Exp Hypertens 2001, 23:177-87.

21. Datté JY, Offoumou MA: Involvement of nitric oxide in fading of 5hydroxy-tryptamine-induced vasocontraction in rat isolated Vena portae smooth muscle. J Pharm Pharm Sci 2004, 23:1-7.

22. Ouedraogo M, Ouedraogo S, Ouedraogo L, Traoré A, Belemtougri GR, Sawadogo LL, Guissou IP: Pharmacological Evaluations for the Relaxant Effect of the Hydroalcoolic extract of Tapinanthus dodoneifolius on rat Trachea. Afr J CAM 2005, 2:166-176.

23. Glaxosmithkline Inc: Monographie du salbutamol Ventolin solution pour perfusion i.v. GlaxoSmithKline Inc; 2007.

24. Michelle M, Cloutier , Craig , Schramm M, Guernsey L: Tannin inhibits the cAMP-b-adrenergic receptor pathway in bovine tracheal epithelium. Am J Physiol Lung Cell Mol Physiol 1998, 274:252-257. 
25. Tanaka Y, Yamashita Y, Horinouchi T, Koike K: Adrenaline produces the relaxation of guinea-pig airway smooth muscle primarily through the mediation of beta (2)-adrenoceptors. J Smooth Muscle Res 2005, 41:153-61.

26. Lindén A, Bergendal A, Ullman A, Skoogh BE, Löfdahl CG: Salmeterol, formoterol, and salbutamol in the isolated guinea pig trachea: differences in maximum relaxant effect and potency but not in functional antagonism. Thorax 1993, 48:547-53.

27. Akah PA, Ezike AC, Nwafor SV, Okoli CO, Enwerem NM: Evaluation of antihistaminic property of Asystasia gangetica leaf extracts. J Ethnopharmacol 2003, 89:25-36

28. de Haas JR, Terpstra JS, van der Zwaag M, Kockelbergh PG, Roffel AF, Zaagsma A: Facilitatory beta2-adrenoceptors on cholinergic and adrenergic nerve endings of the guinea pig trachea. J Am J Physiol 1999, 276:L420-5.

29. Stojković-Andjelković A, Obradović S, Vuletić B, Radlović V: Position anticholinergic drugs in the treatment of childhood asthma. Srp Arh Celok Lek 2010, 138:379-86.

30. Loss JR, Hock RS, Farmer SG, Orzechowski RF: Racemic salbutamol administration to guinea-pigs selectively augments airway smooth muscle responsiveness to cholinoceptor agonists. J Auton Pharmacol 2001, 21:211-7.

31. Ligeron C, Menier L, Meynadier J, Stoebner PE: Thérapeutique dermatologique. Médecine-Sciences Flammarion 2001.

32. Chávez J, Segura P, Vargas MH, Arreola JL, Soto EF, Montaño LM: Paradoxical effect of salbutamol in a model of acute organophosphates intoxication in guinea pigs: role of substance $P$ release. Am J Physiol Lung Cell Mol Physiol 2007, 292:L915-L923.

33. Eksert B, Usta C: Role of the potassium channels in the relaxant effect of levosimendan in guinea pig tracheal preparations. Pharmacological Reports 2009, 61:275-280.

34. Kim DK, Chang SH, Yun IJ, Kwon WK, Woo NS: Salbutamol to facilitate management of acute hyperkalemia in liver transplantation: a case report. Can J Anaesth 2009, 56:142-6.

35. Datté JY, Ziegler A: Pharmacological investigation on nigrescigenin-a cardenolide from Parquetina nigrescens (Afzel.) Bullock: comparative studies on cardiotonic effects of Parquetina nigrescens, g-strophanthin and noradrenaline in guinea-pig isolated atria. J Pharm Pharmacol 2001, 53:859-66.

36. Barnes PJ: Pathophysiology of asthma. British J Clinical Pharmacol 1996, 42:3-10

37. Barnes PJ, Chung KF, Page CP: Inflammatory mediators of asthma: An update. Pharmacological Review 1993, 50:515-595.

38. Ezike AC, Akah PA, Okoli CO: Bronchospasmolitic activity of the extract and fractions of Asystasia gangetica leaves. International Journal of Applied Research in Natural Products 2008, 1:8-12.

39. Souza A, Kadjo KJC, Abo JC, Datté YJ, Traoré F, M'Batchi B: Myostimulating Effect of the aqueous of Khaya senegalensis (Desr) A. Juss. (Meliaceae) in isolated Taenia caeci contractile activity. Current Biocatives compounds 2007, 3:291-294.

40. Rosalia C, Eva Sanz P, Pilar LM, Maria SRL, Mario FG: Mechanisms of relaxation induced by flavonoid ayanin in isolated aorta rings from Wistar rats. Colombia Medica 2010, 41:10-16.

41. Jung WK, Choi I, Oh S, Park SG, Seo SK, Lee SW, Heo SJ, Jeon YJ, Je JY, Ahn CB, Kim JS, Oh KS, Kim YM, Moon C, Choi IW: Anti-asthmatic effect of marine red alga (Laurencia undulate) polyphenolic extracts in a murine model of asthma. Food Chem Toxicol 2009, 47:293-297.

42. Kiessoun K, Souza A, Meda NTR, Yacouba Coulibaly A, Kidrebeogo M, Lamien-Meda A, Lamidi M, Millogo-Rasolodimby J, Nacoulma GO:

Polyphenols content, antioxidant and anti-inflammatory activities of six Malavceae species traditionnaly used to treat hepatitis B in Burkina Faso. European Journal of Scientific Research 2010, 44:570-580.

43. Amos S, Akah PA, Odukwe CJ, Gamaniel KS, Wambede C: The pharmacological effects of an aqueous extract from Acacia nilotica seeds. Phytother Res 1999, 13:683-5.

44. Agbonon A, Aklikokou K, Gbeassor M: Mangifera indica stem bark effect on the rat trachea contracted by acetylcholine and histamine. Pharmaceut biol 2005, 43:475-479.

\section{Pre-publication history}

The pre-publication history for this paper can be accessed here:

http://www.biomedcentral.com/1472-6882/11/23/prepub doi:10.1186/1472-6882-11-23

Cite this article as: Aworet-Samseny et al: Dichrostachys cinerea (L.) Wight et Arn (Mimosaceae) hydro-alcoholic extract action on the contractility of tracheal smooth muscle isolated from guinea-pig. BMC Complementary and Alternative Medicine 2011 11:23.

\section{Submit your next manuscript to BioMed Central and take full advantage of:}

- Convenient online submission

- Thorough peer review

- No space constraints or color figure charges

- Immediate publication on acceptance

- Inclusion in PubMed, CAS, Scopus and Google Scholar

- Research which is freely available for redistribution

Submit your manuscript at www.biomedcentral.com/submit
Biomed Central 